\title{
UMA LEITURA DA NOÇÃO DE VALOR LINGÜÍSTICO EM FERDINAND DE SAUSSURE
}

Denise Lima Gomes da Silva - Doutoranda em Letras (UFPB)

Resumo: O presente trabalho propõe uma discussão sobre a noção de valor lingüístico. Consideramos que, principalmente a partir da descoberta dos manuscritos de Saussure, novos discursos sobre o pensamento saussuriano começaram a surgir, a exemplos dos estudos de Godel (1969), De Mauro (1995) e Bouquet (2000). Nossa discussão tem como base, além do CLG, os Escritos de Lingüística Geral, as anotações de aula dos alunos do Curso de Lingüística Geral e outros estudos que trabalham com a releitura de Saussure. As teses saussurianas ultrapassam fronteiras e ainda hoje se revelam como importantes contribuições para a lingüística.

Palavras-chaves: língua, valor lingüístico, Saussure.

Abstract: This paper proposes a discussion about the notion of linguistic value. Mainly from the findings of the Saussure manuscripts we consider that new discourses on the saussuriean thought had started to appear, such as Godel (1969), De Mauro (1995) and Bouquet (2000) studies. Our discussion is based, besides the CLG, on the Writings in General Linguistics, the students notes on the Course of General Linguistics, and other studies on Saussure. The saussuriean thesis surpasses the borders and are still important today as contributions for the linguistics.

Keywords: language, linguistic value, Saussure.

\section{Introdução}

Paralelamente ao curso de lingüística geral, entre os anos de 1906 e 1909, Saussure dedicou uma boa parte do seu tempo à análise de poesia. Nas pesquisas sobre os anagramas, segundo Starobinski (1971), Saussure preencheu cerca de 150 cadernos de notas sobre verso saturnino, Homero, Virgílio, Lucrécio, Ovídio e a métrica védica. Para o autor, Saussure gastou um tempo considerável e os cadernos são um verdadeiro exercício de decifração.

Nos estudos dos anagramas, conforme Starobinski (1971), Saussure revela que por trás de uma linearidade há algo invisível que desliza entre as visíveis palavras do verso. Starobinski (1971) afirma que existem duas conclusões implícitas na pesquisa de Saussure, uma é a de que as palavras das obras se originam de outras palavras antecedentes e a outra é a de que as palavras antecedentes não são diretamente escolhidas pela consciência formadora. Saussure sugere que os poemas se caracterizariam como um texto sob o texto, um discurso sob o discurso.

Portanto aquilo que existe por trás do verso não é o indivíduo criador, 
consciente, mas o exercício de uma palavra criadora que conduz e induz as relações entre as palavras. Conforme Starobinski (1971, p.16), Saussure observa que aquilo que faz a nobreza da língua assim como a da lenda "é que condenadas uma e outra a se servir apenas de elementos colocados diante delas com um sentido qualquer, elas os reúnem e tiram deles continuamente um novo sentido."

Saussure estaria indicando então a possibilidade de perceber que na produção de um discurso há, no jogo das relações entre as palavras, um sentido que não é previamente determinado e que escapa ao controle da própria produção do discurso.

Vemos que o mesmo movimento de sentido observado nos anagramas também pode ser observado nos estudos de Saussure sobre o sistema lingüístico, na noção de valor. O princípio nuclear de sua lingüústica, o de valor, vem colocar em questão algumas das críticas que afirmam que Saussure desconsiderou o dinamismo da língua. Por isto, uma reflexão sobre a noção de valor lingüístico nos aponta para uma possibilidade de compreender a língua em Saussure como um sistema em constante movimento aberto a rupturas.

Na discussão proposta aqui abordaremos em um primeiro momento o CLG, que durante muito tempo foi considerado a voz oficial de Saussure. Em um segundo momento trataremos da noção de valor lingüístico, tendo como base o CLG, os Escritos de Lingüística Geral, as anotações de aula dos alunos do curso de lingüística geral e pesquisadores que trabalham com a releitura de Saussure. Por fim, discutiremos a noção de valor e a propriedade diferencial do signo lingüístico, enquanto elementos fundamentais para se compreender a dinâmica do sistema da língua.

\section{O CLG: uma imagem de Saussure}

Como nos mostra Calvet (1977) no ano de 1906, no dia 6 de dezembro, Saussure, então professor de gramática comparada e sânscrito, foi convidado a ministrar na Universidade de Genebra duas horas de lingüística geral. O curso foi ministrado em três períodos: no primeiro curso, de janeiro a julho de 1907 (seis alunos matriculados), Saussure abordou a fonologia, a lingüística evolutiva, a etimologia popular; no segundo curso, de novembro de 1908 a junho de 1909 (onze alunos matriculados), Saussure abordou a teoria do signo e da língua, oposição sincronia e diacronia; no terceiro curso, de outubro de 1910 a julho de 1911 (doze alunos matriculados), Saussure tratou da lingüística externa (as línguas).

Em 1916, três anos após a morte de Saussure, a partir dos cadernos de anotações de alguns alunos do curso e alguns escritos pessoais de Saussure, Charles Bally e Albert Sechehaye, com a colaboração de A. Riedlinger, 
publicaram o Curso de Lingüística Geral. A imagem de Saussure passaria à posterioridade ligada à edição do CLG e o mestre ficaria então conhecido historicamente como o fundador da lingüística moderna.

Conforme Faraco (2004) o real impacto do curso acontece no final da década de 1920, principalmente a partir do Primeiro Congresso Internacional de Lingüística em Haia em 1928, do Primeiro Congresso dos Filólogos Eslavos em Praga em 1929, e da Primeira Reunião Fonológica Internacional de Praga em 1930. Nestes três fóruns as teses saussurianas aparecem pelas mãos de Roman Jakobson e Nikolai Troubetzkoy.

Em virtude de sua repercussão histórica e da importância que ocupa na fundação da lingüística moderna, o CLG, durante muito tempo, permaneceu intocado. A integridade do texto não foi colocada em dúvida. Somente a partir da década de 60, com os estudos dos manuscritos de Saussure, novos discursos começaram a surgir nas edições críticas de Engler, Godel e De Mauro. As pesquisas realizadas por eles mostram, além de tudo, que ao contrário do que Bally e Sechehaye deixam transparecer no CLG, o pensamento de Saussure não se revela como algo acabado, mas sim como um pensamento que estava em construção. Apesar dos editores procurarem apresentar os ensinamentos de Saussure como um todo orgânico e definitivo, podemos encontrar, conforme coloca Salum no prefácio da edição brasileira, um Saussure inquieto com as aulas de lingüística geral.

\footnotetext{
Vejo-me diante de um dilema: ou expor o assunto em toda a sua complexidade e confessar todas as minhas dúvidas, o que não pode convir para um curso que deve ser matéria de exame, ou fazer algo simplificado, melhor adaptado ao auditório de estudantes que não são lingüistas. Mas a cada passo me vejo retido por escrúpulos. (SAUSSURE, 1975, p. XVII).
}

O fato de ser uma obra póstuma faz do CLG no mínimo uma obra polêmica. Considerando que são notas de alunos, o CLG dificilmente representa exatamente as palavras de Saussure, mas sim um reflexo da exposição oral do professor. Diante dos cadernos dos estudantes não há dúvidas de que as dificuldades encontradas por Bally e Sechehaye na edição foram diversas, a começar pela busca dos apontamentos de Saussure do curso de lingüística geral. Os editores tinham a intenção de elaborar uma publicação fundamentada na união das anotações de Saussure e as anotações dos alunos. Entretanto pouquíssimo material na época foi encontrado.

Atualmente, as dissonâncias apresentadas entre os textos originais e o CLG, atreladas à forma como o curso foi organizado pelos editores, contribuem para que haja uma tendência em considerar o CLG como uma edição que: ou representa as idéias de Saussure ou as deforma por completo. No entanto, preferimos perceber o CLG, além desta dicotomia, sendo constituído por um movimento que apresenta tanto as marcas de Saussure quanto a dos editores.

Acreditamos, como Silveira (2003), que o CLG traz o pensamento de Saussure, mas o que se perde são os laços internos desse pensamento. E é aí 
que reside toda a dificuldade de em um estudo sobre Saussure, unir os laços perdidos, montar as peças de um quebra-cabeça. Os laços não são fáceis de serem recuperados. Ao lermos os Escritos de Lingüística Geral, por exemplo, nos deparamos com frases inacabadas, espaços em branco, rabiscos. As lacunas deixadas por ele mostram um caminho sinuoso a percorrer.

É dessa forma que observamos a noção de valor lingüístico em Saussure. O valor lingüístico consiste, na teoria saussuriana, em uma das noções mais complexas de se compreender. Em diversas passagens das notas de aula e dos escritos de lingüística geral o conceito de valor aparece relacionado tanto ao termo significação quanto ao termo sentido. Valor e significação se alternam ora enquanto distintos, ora enquanto sinônimos, consistindo em noções difíceis de definir em Saussure.

\section{O valor lingüístico}

Partindo do CLG, vemos que a noção de valor aparece distinta da de significação. O CLG traz uma oposição entre valor e significação, deixando bem claro que a significação não é o valor. O conceito de uma palavra, diz Saussure (1975, p. 134), somente é determinado pelo "concurso do que existe fora dela". Sendo parte de um sistema, a palavra "está revestida de uma significação e de um valor e isso é coisa muito diferente".

No CLG Saussure (1975) afirma que a significação é a contraparte da imagem acústica. A significação está na instância da relação interna do signo, na ordem de tudo aquilo que se passa entre a imagem acústica e o conceito. Tomando o exemplo da palavra julgar, Saussure (1975) explica que dizer que um conceito julgar está unido à imagem acústica julgar, representa a significação.

Saussure também (1975) coloca que na língua todos os termos são solidários, então o signo, resultante da união entre significado e significante, será de igual modo a contraparte de outros signos da língua, o valor então resulta da relação entre signos, emana da presença simultânea de outros signos. O valor é a contraparte dos termos coexistentes. Saussure (1975, p. 135) afirma que o "valor de um termo está determinado por aquilo que o rodeia, nem sequer da palavra que significa sol se pode fixar imediatamente o valor sem levar em conta o que lhe existe em redor, línguas há em que é impossível dizer 'sentar-se ao sol'”. O valor de um termo, então, pode se modificar sem que se altere a significação, apenas pelo fato de um outro termo com quem se relacione tenha sofrido alguma modificação.

Entretanto, podemos perceber que esta distinção trazida pelo CLG não aparece de maneira incisiva nos textos originais. Nos textos, valor e significação ora se assemelham, ora se distinguem.

Conforme as anotações de Riedlinger (1969), Saussure coloca que o valor 
não é a significação. O valor é dado além da significação, pela relação que mantém com os outros termos, pela situação recíproca entre os termos. O valor de uma palavra apenas é determinado por aquilo que a rodeia. A noção de valor então aparece distinta da noção de significação da mesma forma que está no CLG.

De acordo com as anotações de Dégallier (1969), Saussure, retomando a figura do signo lingüístico, indica que a significação é a contraparte da imagem acústica. Entretanto, logo em seguida, observa que a significação que aparece no primeiro momento como a contraparte da imagem acústica é ao mesmo tempo a contraparte dos termos coexistentes. Levando em consideração que o valor de uma palavra resulta somente da coexistência de diferentes termos, então pergunta Saussure: poderia o valor se confundir com a contraparte de imagem acústica? Ou seja com a significação? Saussure coloca que as duas relações são muito difíceis de distinguir

A mesma preocupação é demonstrada por Saussure nas anotações de Constantin

(1993) em que coloca que a significação como a contraparte da imagem acústica e a significação como contraparte de termos coexistentes se confundem e que é muito difícil em quaisquer domínios dizer em que consiste o valor. Vemos que valor e significação assumem as mesmas características e aparecem enquanto sinônimos.

Em seguida, ainda nas anotações de Constantin (1993) vemos Saussure delimitar a noção de valor dizendo que o valor é determinado por um princípio paradoxal. O valor é constituído: 1) por uma coisa dessemelhante que podemos trocar; 2) por uma coisa semelhante que podemos comparar. Estes dois elementos são essenciais na noção de valor. Tomando o exemplo da moeda de 20 francos, Saussure explica que seu valor está numa coisa dessemelhante que pode ser trocada, como por exemplo, pão; e uma coisa semelhante que pode ser comparada, como por exemplo, com outras moedas de um franco, dois francos. O valor seria a contraparte de uma, ao mesmo tempo em que seria a contraparte da outra.

Conforme Godel (1969), em Saussure a complexidade da noção de valor lingüístico consiste no fato de que o valor depende de três tipos de relações: uma relação interna do signo; uma relação dos termos in absentia e uma relação dos termos in praesentia. As duas primeiras relações são conseqüências da arbitrariedade e acontecem no eixo paradigmático e a última é conseqüência do caráter linear da língua e acontece no eixo sintagmático.

A relação interna do signo consiste na relação entre imagem acústica e o conceito. A relação in absentia é a relação associativa e acontece no eixo paradigmático, em que não existe uma extensão temporal e espacial. Nas relações associativas, um termo chama uma série de outros termos que mantém com ele algum tipo de semelhança, a relação une os termos in absentia numa série mnemônica virtual, constitui a memória da língua. 
No eixo paradigmático, as palavras se assemelham das mais diversas formas. Saussure (1975) dá alguns exemplos das possíveis semelhanças. Nas palavras ensinamento, ensinar, ensinamos, ensina, temos um elemento em comum que é o radical, em contrapartida no caso das palavras ensinamento e armamento, o elemento em comum é o sufixo. A semelhança pode ser também entre significados apenas, a exemplo de ensinamento, instrução, aprendizagem, educação. Ou entre imagens acústicas, a exemplo de blu, durchbleuen (que se pode exemplificar em português como agosto e a gosto).

A relação in praesentia é aquela que acontece no eixo sintagmático, entendendo o sintagma como tudo aquilo que é da competência do caráter linear da língua, espacial e temporal. As palavras se alinham uma após outra, em uma única extensão, em uma única dimensão tempo espacial, mantendo entre si uma relação de oposição.

Em Godel (1969), Saussure não faz a separação entre as relações in absentia e in praesentia, o valor existe, e é determinado de acordo com os dois eixos concomitantemente, o valor de uma palavra resultará sempre do agrupamento paradigmático e do agrupamento sintagmático. Saussure assim coloca:

unidades de associação

(grupos no sentido de famílias)

e

Na unidade de um grupo de associação (dominas, domino, désireux, malheureux, chanceux...) há sempre um elemento variável e um elemento constante. [...] um sintagma, ao contrário, comporta uma ordem, um seqüência linear, qualquer que seja sua grandeza (palavra analisável, composta, frase). O mecanismo consiste em empregar tipos de sintagmas que temos em mente, pondo em jogo os grupos de associação para aportar a diferença desejada. [....] Todo valor resulta desse duplo agrupamento.(GODEL, 1969, p.72) ( tradução nossa)

Portanto podemos perceber que o valor de uma palavra é determinado por uma relação paradigmática, mas também, e ao mesmo tempo, por uma relação sintagmática, o valor então seria fruto da interseção destes dois eixos.

Conforme as anotações de Constantin (1993), Saussure coloca que o sistema ao qual os termos pertence é uma das fontes de valor. Então quais outras fontes de valor haveriam?

No CLG vemos Saussure (1975) colocar que a coletividade é necessária para estabelecer os valores, cuja razão de ser está no consenso e no uso. A mesma posição é também reafirmada nos Escritos de Lingüística Geral quando Saussure explica que a coletividade deve ser considerada um dos elementos internos e não externos. É a coletividade que gera o valor, o que significa pensar que o valor não existe nem antes nem fora da coletividade, o valor não pode ser estabelecido isoladamente. Para Saussure (2004) o sistema de signos é feito para a coletividade, assim como o barco é feito para o mar.

Godel (1969) defende que há em Saussure a idéia de duas fontes de valor. Uma fonte de valor que é o sistema e outra fonte de valor que é a coletividade. A partir daí sugere que poder-se-ia pensar em duas ordens de valor: valor 
recíproco e valor em si. O valor recíproco seria resultado do sistema, fruto do jogo das relações entre os termos e o valor em si seria resultado da coletividade.

Tomamos então o exemplo da palavra sol. O valor da palavra sol resulta do jogo de relações de diferenças e oposição entre os termos, mantido no sistema da língua, o seu valor é outorgado pela força social que o sanciona, assim uma parte do valor da palavra sol é fixado pela coletividade (o valor em si), mas ao mesmo tempo, em estando no sistema da língua, a palavra sol permanece em relação recíproca com os outros termos, a relação recíproca entre os termos possibilitará que o seu valor (o valor em si) nunca esteja totalmente determinado.

Saussure (2004) é bastante enfático na idéia de que o valor de um termo nunca está totalmente determinado, os termos são pela relação de diferença e oposição que mantém no sistema da língua.

Saussure (1975) explica que se as palavras fossem encarregadas de representar previamente os conceitos, cada uma delas possuiria, de uma língua para a outra, correspondentes exatos, mas isto não acontece. Para Saussure (1975) aquilo que emana do sistema da língua não são idéias dadas de antemão, mas sim valores "puramente diferenciais, definidos não positivamente por seu conteúdo, mas negativamente por suas relações como os outros termos do sistema. Sua característica é ser o que os outros não são". (SAUSSURE, 1975, p.136).

\section{A dinâmica da língua}

O princípio da diferença segundo Saussure (1975) é tão essencial que pode ser aplicado a todos os outros elementos materiais da língua, inclusive aos fonemas. Saussure (1975) explica que cada idioma compõe suas palavras baseado em um sistema de elementos sonoros. Cada um destes elementos forma unidades que são delimitadas. No entanto, aquilo que caracteriza os fonemas não é a sua qualidade própria e positiva, mas sim o fato de não se confundirem entre si, assim, "os fonemas são, antes de tudo, entidades opositivas, relativas e negativas".(SAUSSURE, 1975, p.138)

O significante lingüístico diz Saussure (1975) não é de maneira nenhuma algo fônico, e sim algo incorpóreo, a sua essência não é constituída por uma substância material, mas unicamente por diferenças que vão separar uma imagem acústica da outra.

De Mauro (1995, nota 65) observa que o sistema de valores da língua é algo diferente das realizações fônicas (fônico-acústico) e significativas (lógicopsicológico) dos atos particulares da fala. O autor sugere que se tomarmos como base de identificação a realidade fônica e a realidade lógico-psicológica das significações naquilo que elas valem, ou seja, o seu valor, pode-se dizer que os valores das fonias são os significantes da língua e os valores das significações 
são os significados. Tais valores não sendo determinados, sendo arbitrários tanto do ponto de vista fônico-acústico quando do ponto de vista lógicopsiológico, se delimitam reciprocamente e formam um sistema. O sistema de valores por conseguinte não é formado de materiais fônico-acústicos e lógicopsicológicos, mas sim de figuras determinadas de tais materiais, sendo portanto uma forma. A forma é abstrata, sendo somente concreta do ponto de vista da consciência dos interlocutores quando falam.

Vemos que segundo Saussure (2004) o valor exprime melhor do que qualquer outra palavra, a essência da língua: o fato de que uma forma não significa, mas vale, e se ela vale, ela implica na existência de outros valores. Sendo assim aquilo que faz a identidade de uma rua demolida e reconstruída novamente não é o seu aspecto material, mas sim o fato dela ter o mesmo valor.

A noção de valor lingüústico nos faz compreender a língua enquanto sistema completamente desprovido de substância, funcionando apenas como formas que se definem pela pura diferença. Entretanto, podemos observar que a noção da língua que funciona pela diferença é marcada em Saussure por uma certa positividade.

No CLG Saussure (1975, p. 139) considera que na língua existem apenas diferenças sem termos positivos. "Quer se considere o significado, quer o significante, a língua não comporta nem idéias nem sons preexistentes ao sistema lingüístico, mas somente diferenças conceituais e diferenças fônicas resultantes deste sistema".

No entanto, Saussure (1975, p.139) alerta que o signo tomado em sua totalidade é considerado um fato positivo e que "dizer que na língua tudo é negativo só é verdade em relação ao significante e ao significado tomados separadamente: desde que consideremos o signo em sua totalidade, achamo-nos perante uma coisa positiva em sua ordem.". De Mauro (1995) observa que esta passagem é de grande importância teórica, pois ao dizer que o signo é uma entidade positiva Saussure o coloca como uma entidade concreta.

Saussure (1975) acrescenta ainda que quando se comparam os signos entre si (termos positivos) não se pode mais falar de diferença, mas sim de oposição. Observamos que ao distinguir diferença de oposição, Saussure (1975) considera que a relação existente entre significado e significante acontece por diferença, e a relação entre um signo e outro acontece por oposição.

Silveira $(2003$, p.56) referindo-se a estas passagens do CLG observa que:

é preciso notar que em determinado momento, a diferença é dada como propriedade dos elementos lingüísticos, embora a diferença só se constitua em uma relação, já no outro momento, trata-se da diferença unicamente enquanto relação e na possibilidade de haver distinção. Ou seja, pode ser uma relação de diferença ou de oposição sem com isso alterar a propriedade do que está em um ou outro tipo de relação.

O signo considerado em sua totalidade é uma coisa positiva, fruto da combinação da relação de diferença entre o significante e o significado. Tomado 
no sistema da língua, o signo mantém com os outros signos uma relação de oposição. Diferença e oposição não são da mesma natureza, mas constituem o signo, "a primeira se sustenta no principio da negatividade (ser o que os outros não são), a segunda requer alguma positividade para que haja oposição" (SILVEIRA, 2003, p.57).

No entanto, embora constituam relações distintas, percebe-se que a relação de oposição entre os signos conserva a propriedade da negatividade. Tal concepção se torna clara quando Saussure $(2004$, p.68) analisando a questão da negatividade da sinonímia dá o seguinte exemplo:

O sol parece representar uma idéia perfeitamente positiva, precisa e determinada, assim como a palavra lua: entretanto, quando Diógenes diz a Alexandre "Sai da frente do meu sol!", não há mais, em sol, nada de sol a não ser a oposição com a idéia de sombra, e a própria idéia de sombra é apenas a negação combinada da idéia de luz, de noite fechada, de penumbra, etc, acrescentada à negação da coisa iluminada com relação ao espaço obscurecido.Retomando a palavra lua, pode-se dizer a lua aparece, a lua cresce, a lua decresce, a lua se renova, semearemos na lua nova (...)

Saussure observa que (2004, p. 68-69) tudo o que "pomos em lua é absolutamente negativo, vindo apenas da ausência de um outro termo". Não é a idéia positiva contida em lua ou sol, em água, ar ou árvore, mas o fato de que todas essas denominações são igualmente negativas, " significam apenas com relação às idéias inseridas em outros termos (igualmente negativos), não tem, em nenhum momento, a pretensão de se aplicar a um objeto definido em si”. Há então na língua uma tensão que se estabelece entre o UM e o NÃO-UM. A negatividade faz como que haja sempre na língua uma ausência e portanto uma possibilidade de acontecimento.

\section{Considerações finais}

Qualquer tentativa de conclusão em Saussure seria falha. Saussure nos deixou um enorme quebra-cabeça que ainda precisa ser decifrado, ou pelo menos a ilusão de que pode ser decifrado.

Partindo do CLG, vimos que a noção de valor lingüístico parece incisiva se opondo a noção de significação. Entretanto os estudos de Godel (1969) e as anotações de aulas de Constantin(1993) e de Dégallier(1969) mostram um professor inquieto que parece ter refletido por muitas vezes a questão. A noção de valor lingüístico se constitui em um duplo movimento de formulação e reformulação, de aproximação e distanciamento. Os questionamentos de Saussure sobre o valor lingüístico aparecem opacos no CLG.

Em um segundo momento, vimos que a noção de valor lingüístico traz para o signo uma propriedade diferencial. O fato de que uma forma não significa, mas vale pela diferença, e se ela vale, ela implica na existência de outros valores, nos leva a pensar que a noção de valor lingüístico provê uma língua em movimento constante, aberta a rupturas. A concepção de valor leva à compreensão de que 
a língua em Saussure não é um sistema estático, é um sistema dinâmico e em constante movimento, onde o inesperado acontece

Sendo o valor relativo, então o valor de uma palavra não está totalmente determinado, há sempre a possibilidade de um mais ainda. È justamente o caráter relativo do valor, baseado na diferença que faz com que a língua seja um sistema dinâmico, em que o sentido como coloca Starobinski (1971) é resultado do emprego combinatório, um produto variável e não um dado prévio.

\section{Referências}

BOUQUET, Simon. Introdução à leitura de Saussure. Tradução Carlos A. L. Salum e Ana Lúcia Franco. São Paulo: Cultrix, 2000.

CALVET, Louis Jean. Saussure: pró e contra para uma lingüística social.

Tradução M.E.L.Salum, São Paulo: Cultrix, 1977.

CONSTANTIN, Emile. Saussure's third course of lectures on general

Linguistics. In: KOMATSU, Eisuke; HARRIS, Roy. (Eds.).Saussure's third

course of lectures on general linguistics (1910-1911): from the notebooks of Emile Constantin. Oxford: Pergamon Press, 1993.

DÉGALLIER.G. Cahiers d'etudiants. Cours de linguistique générale. In: GODEL, Robert. Les sources manuscrites du cours de linguistique générale de F. de Saussure. 2.ed. Genebra: Librairie Droz S.A, 1969. p. 76-92 DE MAURO, Tullio. “Notas”. In: SAUSSURRE, Ferdinand. Cours de

Linguistique Générale. 4.ed. Paris: Payot, 1995. (notas traduzidas/ não paginado)

DOSSE, François. O corte saussuriano. In: DOSSE, François. História do estruturalismo. Vol I, Campinas: Editora da Unicamp, 1993.

FARACO, Carlos Alberto. Estudos pré-saussurianos. In. MUSSALIN e BENTES.

Introdução à lingüística: fundamentos epistemológicos. Livro 3. São Paulo: Cortez, 2004.

GADET, Françoise. Saussure une science de la langue. Paris: Presses Universitaires de France,1987.

GODEL, Robert. Les sources manuscrites du cours de linguistique

générale de F. de Saussure. 2.ed. Genebra: Librairie Droz S.A, 1969.

RIEDLINGER.A. Cahiers d'etudiants. Cours de linguistique générale. In: GODEL, Robert. Les sources manuscrites du cours de linguistique générale de $F$. de Saussure. 2.ed. Genebra: Librairie Droz S.A, 1969. p. 53-73 SAUSSURE, Ferdinand. Curso de Lingüística Geral. Tradução de Antônio Chelini, José Paulo Paes e Izidoro Blikstein 7.ed. São Paulo: Cultrix, 1975.

SAUSSURE, Ferdinand. Escritos de Lingüística Geral. Org. Bouquet Simon; Engler Rudolf. São Paulo: Cultrix, 2004.

SILVEIRA, Eliane Mara. As marcas do movimento de Saussure na fundação da lingüística. São Paulo, 2003. Tese (Doutorado em Lingüística) - Universidade Estadual de Campinas, Instituto de Estudos da Linguagem.

STAROBINSKI, Jean. As palavras sob as palavras: os anagramas de Ferdinand Saussure. Trad. Carlos Vogt. São Paulo: Perspectiva, 1971.

\footnotetext{
[i] des unités d'association (groupes au sens de familles) et des unités discursives (groupes au sens de syntagmes). Dans l'unité d'un groupe d'association (dominus, domino; désireux, malheureux, chanceux), il y a toujours un élément variable et un élément constant. [...] Un syntagme, au contraire, comporte un ordre, une suite linéaire, quelle qu'em soit l'ampleur (mot analysable, composé, phrase). Le mécanisme consiste à employer des types de syntagmes que nous avons en tête, en faisant jouer les groupes
} 
d'association pour amener la différence voulue [...] Toute valuer résulte de ce double groupement 